\title{
Fanzine Ovo de Colombo e a identificação cultural do design em Curitiba no início da década de $1990^{1}$
}

\author{
Fanzine Ovo de Colombo and the design cultural identification in Curitiba at the \\ begging 1990 decade
}

Ana Paula França ${ }^{2}$

\begin{abstract}
RESUMO
O design como atividade profissional ainda não é discernível socialmente, sendo sua definição e reconhecimento pontos de discussão constantes em pautas e ações para o fomento da área no Brasil. O tema deste artigo relaciona-se com essa incessante necessidade de afirmação que alimenta a constituição de uma identificação cultural. O recorte temporal definido visa contemplar um momento crucial desse processo, pois no início da década de 1990 o campo profissional em questão é marcado por novos posicionamentos e alianças. Iniciativas coletivas como associações profissionais em São Paulo e Rio de Janeiro acabaram extintas, enquanto em Curitiba uma série de ações inéditas era desenvolvida. O primeiro Encontro Nacional de Estudantes de Design ( $\mathrm{N}$ Design) compõe esse quadro, destacando-se pelo intuito de integrar os alunos brasileiros em prol de uma coesão que o âmbito profissional não mais apresentava. Este artigo estuda uma das primeiras ações empreendidas pelos alunos do Centro Acadêmico de Design da Universidade Federal do Paraná, tendo em vista a realização efetiva do evento, o fanzine Ovo de Colombo. A publicação tinha como objetivo estimular a adesão de alunos de universidades brasileiras, exaltando a necessidade da constituição de um fórum de discussão em torno da situação do design e do ensino do design no país. A abordagem proposta neste trabalho, portanto, destaca as estratégias de identificação articuladas pelos realizadores do Ovo de Colombo, considerando-as parte constitutiva de um processo de identificação cultural mais amplo e bastante significativo para a compreensão da formação de uma cultura do design no Brasil.

Palavras-chave: História do design. Cultura do design. Fanzine Ovo de Colombo.
\end{abstract}

\begin{abstract}
Design as a professional activity is not yet discernible socially, its definition and recognition are constant points of discussion in staves and actions to foster the area in Brazil. This articles subject relates to this incessant need of self-assertion that nurture the formation of a cultural identification. The temporal cutting defined seeks to contemplate a crucial moment of this process, since in the beginning of 1990 decade, the professional field in question is marked by new positioning and alliances. Class actions like professional associations in São Paulo and Rio de Janeiro ended up extinguished, while in Curitiba a series of unheard class actions were developed. The first National Design Students Meeting (N Design) compose this scenario, standing out through the intention to integrate Brazilian students, promoting a cohesion that the professional scope no longer presented. This article envisages to one of the first actions taken by the students of "Centro Acadêmico de Design da Universidade Federal do Paraná", bearing in mind the effective realization of the event, the Ovo de Colombo fanzine. The publication had the objective to stimulated Brazilian university students to adhere, exalting the need to a discussion forum around the design and design teaching situation in the Country. The proposed approach in this paper, therefore, highlights the identification strategies articulated by the "Ovo de Colombo" creators, considering them as integrating part of a wider cultural identification process and very meaningful to the comprehension of Brazils design culture formation.

Keywords: History of design. Culture of Design. Fanzine Ovo de Colombo.
\end{abstract}

\footnotetext{
1 Trabalho apresentado no dia 16 de outubro de 2013, no Grupo de Trabalho 7 - Design e Cultura.

${ }^{2}$ Mestre em Artes Visuais - Universidade Positivo. E-mail: anapaulafranca@up.com.br
} 


\section{INTRODUÇÃO}

Abordar o design geralmente implica na apresentação inicial de definições, seguida por uma lista de atribuições dos designers. Isso ocorre porque a atividade e, consequentemente, a classe profissional, estabelecida com o auge da Revolução Industrial em muitos países, ainda não é socialmente reconhecível. Do ponto de vista dos designers, o quadro agrava-se devido ao uso demasiado e ampliado do termo design. Como reação a esse uso democrático, "não faltam no meio profissional definições para o design, e essa preocupação definidora tem suscitado debates infindáveis." (CARDOSO, 2008, p. 20)

Considerando esse quadro, estudar o desenvolvimento do design mostra-se tarefa complexa, sendo os próprios limites do tema bastante discutíveis. Relacionada a essas idiossincrasias encontra-se o caráter embrionário da pesquisa histórica sobre o design no Brasil. Consequentemente, a área apresenta um amplo campo de possibilidades e a recente historiografia sobre o tema conta com empreendimentos que representam frentes distintas. Aqui, parte-se do ponto de vista do professor e estudioso inglês Guy Julier, considerando-se a história do design "como a história de diversos grupos e indivíduos que trataram de separar o design de outras práticas culturais e comerciais." (JULIER, 2010, p. 64)

Em Curitiba, no inicio da década de 1990, uma série de ações com o intuito de dar visibilidade ao design e, consequentemente, alimentar o processo de identificação da atividade profissional, são realizadas. Nesse certame, localiza-se o primeiro Encontro Nacional de Estudantes de Design, o $\mathrm{N}$ Design, evento organizado e viabilizado pelos alunos do Centro Acadêmico de Desenho Industrial da UFPR (CADI/UFPR), ocorrido em julho de 1991.

Defende-se que o evento é um objeto privilegiado para o reconhecimento do processo de identificação do design no período em questão, destacando-se sua vinculação a uma série de elementos constituintes do cenário local, como a I Bienal Brasileira de Design, as sementes do Centro de Design do Paraná (na época chamado Centre de Design do Paraná) e a coluna Design Designer (iniciada em 1988 e publicada no jornal O Estado do Paraná).

Neste artigo, a abordagem do primeiro $N$ Design delineia-se como uma interpretação das três primeiras edições do fanzine Ovo de Colombo, criadas pelo 
grupo de alunos que organizou a primeira edição do evento. As edições em questão circularam no final de 1990 e pretendiam angariar o apoio de estudantes de outras universidades, garantindo o sucesso da empreitada.

Considera-se, portanto, os exemplares selecionados como documentos históricos, seguindo as indicações da história cultural e sua reverência a vestígios e fragmentos do passado pouco explorados tradicionalmente.

\section{FANZINE OVO DE COLOMBO: UMA QUESTÃO DE IDENTIFICAÇÃO}

Fanzines são publicações criadas por jovens ou grupos de jovens com o intuito de compartilhar informações com seus pares, ou seja, com aqueles que demonstram interesses comuns sobre algum assunto específico. Inicialmente, ainda na década de 1930, os fanzines foram utilizados por leitores de histórias de ficção para divulgar seus trabalhos autorais fora do circuito profissional e comercial, nos Estados Unidos. Já nos anos de 1960 e 1970, serviram como canal para expressar desde ideais libertários do maio de 1968 à máxima punk do "faça você mesmo". (MUNIZ, 2010, p. 15).

Independente da diversidade de assuntos e temas propagados pelos fanzines, de maneira geral, esse tipo de publicação apresenta como escopo a condição marginal de sua produção e circulação. "O desejo de produzir e ver o material pronto é urgente" e, desse modo, escapa-se de uma diagramação convencional, seguindo as regras de editoração características de publicações comerciais. (GALVÃO, 2010, p. 82)

Tesoura, cola, e máquina fotocopiadora são os principais recursos na composição e montagem de textos e imagens, autorais ou oriundos de fontes préexistentes. Vincos, dobras, cortes especiais, configuram seções espaciais pouco usuais, descoladas de um único sentido de leitura. Além disso, segundo Demetrios Galvão, uma prática comumente associada ao fanzine é o fato de o leitor poder tornar-se colaborador, sendo as dimensões hierárquicas, burocráticas desmanchadas e as associações compostas ao longo do processo, a cada nova publicação. (GALVÃO, 2010, p. 84) 
A primeira edição do fanzine Ovo de Colombo oferecia um pequeno retângulo de papel (4,0 x 2,5 cm), avulso, sendo uma das faces ocupada por um pequeno ovo desenhado à mão. Em uma das bases do retângulo havia um vinco e um corte que permitia que o ovo fosse "colocado em pé".

A expressão "ovo de Colombo" faz menção a uma anedota, popularizada em meados do século XVI. Ilustra o fato de que problemas aparentemente insolúveis parecem facilmente resolvíveis depois que a solução é apresentada. A versão mais difundida afirma que, ao ser laureado sobre seus grandes feitos, Cristovão Colombo propôs um desafio aos seus interlocutores: colocar um ovo em pé. Sem o sucesso daqueles que aceitaram o desafio, Colombo quebrou uma das extremidades do ovo e efetivou a saída instigada.

Em outra versão para a origem da famosa história, atribui-se a Filippo Bruneleschi, famoso arquiteto renascentista, o uso do desafio para demonstrar as possibilidades da engenhosidade humana (VASARI, 2011, p. 236). O arquiteto conseguiu finalmente convencer os órgãos competentes da potência de seu projeto para a construção da cúpula da catedral Santa Maria Del Fiore ao colocar o ovo em pé, demonstrando que a solução proposta por ele para o problema pareceria óbvia depois de efetivada, pois seria o resultado de ações lógicas, viáveis e simples.

Mas qual seria o motivo para o uso do recurso metafórico pelos autores do fanzine em questão? Qual era o ovo que os alunos do curso de Desenho Industrial da UFPR teriam que colocar em pé, efetivamente?

Desde a primeira edição, os autores do fanzine deixam claro que a iniciativa esteve diretamente relacionada à missão de viabilizar o primeiro Encontro Nacional de Estudantes de Design. Com data prevista para julho de 1991, o encontro seria realizado em Curitiba, mas, o caráter nacional, almejado desde o início, exigiria o envolvimento e contribuição de alunos de design de outras universidades do país. A publicação, portanto, foi concebida como um meio para construir a necessidade do evento, assim como convocar os estudantes de design a assumir seu papel social dentro de um projeto coletivo.

Devido a esses aspectos, considera-se o fanzine Ovo de Colombo como uma prática discursiva identitária, como uma estratégia em um processo de identificação do design no início da década de 1990, em Curitiba. Essa consideração escapa, portanto, do naturalismo que o termo identidade pode sugerir, assumindo, 
em contrapartida, o ponto de vista de Stuart Hall sobre a questão. Segundo o pesquisador, parte-se do princípio que a abordagem discursiva da identidade considera o processo de identificação como uma construção. (HALL, 1995, p. 106) Assim, o termo identidade implica menos em um conjunto de características comuns, pretensamente essenciais, do que

(...) ao ponto de encontro, o ponto de sutura, entre, por um lado, os discursos e as práticas que tentam nos "interpelar", nos falar ou nos convocar para que assumamos nossos lugares como sujeitos sociais de discursos particulares e, por outro lado, os processos que produzem subjetividades, que nos constroem como sujeitos aos quais se pode "falar". As identidades são, pois, pontos de apego temporário às posições-desujeito que as práticas discursivas constroem para nós. Isto é, as identidades são as posições que o sujeito é obrigado a assumir, embora "sabendo" (aqui, a linguagem da filosofia da consciência acaba por nos trair), sempre, que elas são representações (...). (HALL, 1995, p. 112)

Desse modo, a abordagem aqui empreendida pretende trazer à tona quais foram "os pontos de apego temporários" demarcados pelo fanzine Ovo de Colombo e, assim, destacar as "posições-de-sujeito" que o discurso em questão negociava com aqueles que tinham acesso à publicação.

Para tanto, não se pode deixar de considerar, segundo Stuart Hall, que a compreensão das identidades deve partir do fato de que as mesmas são produzidas em locais históricos e institucionais específicos, no interior de formações e práticas discursivas específicas, por estratégias e iniciativas específicas. (HALL, 1995, p. 109)

\subsection{Interação com um campo em construção}

O fanzine Ovo de Colombo como prática discursiva específica faz parte de um conjunto de outras práticas em desenvolvimento em Curitiba, no início da década de 1990.

Segundo Pierre Bourdieu, a análise da essência da especificidade de qualquer expressão humana é inseparável da afirmação de autonomia do campo de produção que ela supõe e, ao mesmo tempo, reforça. (BOURDIEU, 2012, p. 70) Sendo assim, pode-se afirmar que uma história propriamente do design existe somente porque os designers e os seus produtos se acham objetivamente situados 
por um campo, ou seja, em relação a outros designers e aos produtos de outros designers.

Nesse sentido, destacam-se esforços múltiplos para a construção de um campo para o design, fora do eixo Rio-São Paulo, onde as ações fomentadoras que serviam de referência até então, estavam em decadência. Segundo Marcos Braga, a extinção de associações como a ABDI no Rio de Janeiro, entre o final dos anos 1980 até 1998, deve-se a desvalorização da ação coletiva, sendo o cenário econômico e político neoliberal ingredientes para a busca da consolidação de carreiras e conquistas profissionais individuais. (BRAGA, 2011, p. 266)

O pesquisador Guy Julier, defensor de uma disciplina denominada Cultura do Design, afirma que ao lado do processo de profissionalização do designer está a proliferação de instituições dedicadas à promoção de diversos aspectos do design, assim como a sistematização e salvaguarda de sua prática." (JULIER, 2010, p. 66) O estudioso reconhece, portanto, a relevância de uma "autoconsciência", de uma "vontade de design" ou "designeriness" (JULIER, 2010, p. 64) para a compreensão do modo como o design age ativamente na constituição social. Segundo ele, a designeriness está calcada em práticas compartilhadas, componentes de um acervo de convenções e procedimentos que constituem uma estrutura de relações objetivas, denominada campo.

Nesse sentido, um elemento de relevo no "campo" curitibano foi a coluna Designdesigner, única do gênero no país, publicada desde meados da década de 1980 até o fim da primeira década dos anos 2000. Seu autor, Ivens Fontoura, professor dos cursos de design da UFPR e PUC-PR, funcionava como um verdadeiro agitador cultural, promovendo ações para além das páginas do jornal $\mathrm{O}$ Estado do Paraná, como exposições, cursos livres, palestras, prêmios, etc.

Em matéria publicada em 09 de setembro de 1990, Ivens Fontoura afirma que o eixo Rio-São Paulo está pequeno diante da grandeza do país, sendo Curitiba "exemplar em inúmeros segmentos do conhecimento e da organização social" (FONTOURA, 1990, p. 7). Sua intenção é destacar a relevância da capital paranaense no âmbito do design, por isso segue o artigo enumerando as ações por aqui difundidas: Mostra Gráfica Brasil 89, A revista Gráfica de Oswald Miran e, especialmente, a I Bienal Brasileira de Design. 
A frente do último empreendimento citado, o professor Ivens Fontoura dedica também a maioria de suas matérias, publicadas no segundo semestre de 1990. Projetos premiados e designers renomados, assim como seções especiais dedicadas a história e desenvolvimento do design no Paraná são destacados nos artigos do período.

Em mais de uma ocasião, Ivens Fontoura ressalta o título recémconquistado por Curitiba, "capital brasileira do design", como consequência direta da realização da I Bienal Brasileira de Design. Segundo o autor, o título deve-se, por um lado, ao reconhecimento de "sua dinâmica como cidade capaz de modificar-se por si própria com a participação de seu povo e de seus governantes e de motivar transformações de outras cidades brasileiras". Por outro lado, o título deve-se também "a constatação de que distintos acontecimentos e ações em torno do design a fazem se destacar das demais". (FONTOURA, 1990, p. 8).

A admirável disposição para engendrar esses eventos, demonstrada por Ivens Fontoura, certamente marcava também sua atuação como docente. Durante a I Bienal, alunos de outras instituições visitaram Curitiba, sendo, muito provavelmente, a potencialidade desse intercâmbio, indicada pelo mestre aos seus aprendizes. Diante do quadro delineado, os alunos do curso de design paranaense estavam suscetíveis a assumir o propósito de trazer mais um "acontecimento em torno do design" para Curitiba, assegurando assim seu recente título.

\section{MATERIALIZAÇÃO DA ESTRATÉGIA IDENTITÁRIA}

As três edições do fanzine Ovo de Colombo dialogam de maneira íntima com a coluna Designdesigner do professor Ivens Fontoura. Na primeira edição há inclusive uma montagem com a imagem fotográfica do rosto do professor e o símbolo da I Bienal Brasileira de Design, seguida dos dizeres: "Este é o Ivens, o 'cara' da Bienal - As nossas homenagens ao evento."

A teorização em torno da ideia do fanzine como "design postal" também indica a simbiose entre os dois veículos editoriais e seus autores. Em 28 de outubro de 1990, Ivens Fontoura "faz o lançamento oficial de uma nova forma de se fazer design e de comunicação entre profissionais e estudantes da área" em sua coluna 
publicada sempre aos domingos. Na mesma matéria, trata da principal incumbência do fanzine indicando que "um grupo de estudantes de design da UFPR liderados por Naotake Fukushima, Ken Fonseca, Edu Otávio Jr. e Evilásio Viana está se movimentando para organizar efetivamente" o primeiro Encontro de Estudantes de Design. Completa exaltando que "da mesma maneira que o Paraná correu na frente para conquistar o espaço e realizar a I Bienal Brasileira de Design, eles tentarão por em prática efetiva a tentativa ensaiada a partir de 1985, em Belo Horizonte, por ocasião do IV Encontro Nacional de Designers." (FONTOURA, 1990, p. 2)

A proposta do fanzine Ovo de Colombo, portanto, pode ser encarada como resposta a um chamamento que deveria compor um quadro de ações legítimas, politicamente visíveis e socialmente reconhecidas. Em suma, os estudantes deveriam pegar carona na onda de otimismo frente à afirmação de Curitiba como "capital brasileira do design" (segundo Ivens Fontoura) e mostrar que trariam para a cidade mais uma conquista.

Foi efetivamente o que aconteceu. Em julho de 1991, o primeiro Encontro Nacional de Estudantes de Design, batizado posteriormente de $\mathrm{N}$ Design foi realizado, no Centro de Criatividade de Curitiba. Em decorrência do sucesso da primeira edição, ocorrida entre 15 e 20 de julho, o N Design tornou-se periódico. Atualmente, somam-se vinte duas edições, sendo que cidades de diversos estados do país já serviram como sede nesse ínterim.

Entretanto, nota-se que a escolha da linguagem do fanzine como angariadora do encontro relaciona-se com a crença de que o evento não poderia ser reduzido a uma ação meramente institucional, abrindo mão do caráter questionador, crítico, lúdico, ou seja, jovem. Esse fundamento pode ter sido decisivo para que o vindouro evento fosse divulgado de modo a amenizar seu caráter operacional, assim como seus aspectos burocráticos.

Destaca-se que a materialização dessa estratégia, nos exemplares contemplados, é efetivada, principalmente, por dois pontos fundamentais: 1) o layout em si, principalmente pela definição da hierarquia na relação fora/dentro da publicação, 2) e o uso de recursos tipográficos e ilustrações, variando entre a utilização de meios mecânicos, neutros, e a articulação de recursos gestuais e remixados. Aponta-se que a definição desses dois fatores foi articulada de modo que 
os conteúdos mais formais, oriundos de meio oficial e legitimado, fossem distinguidos e/ou diluídos na constituição da prática discursiva alternativa.

Como já foi anteriormente ressaltado, escapar de layouts convencionais está ligado ao caráter contestador do fanzine. Em contrapartida, nota-se que a estrutura instituída por meio de cortes e dobras das primeiras edições do Ovo de Colombo não evita a indicação de um sentido de leitura privilegiado. O modo como o fanzine é "fechado", a definição da capa e do verso, acabam por indicar um modo de ler dominante (apesar de não inteiramente irreversível). Assim, as áreas mais interiores, a serem desvendadas à medida que o objeto é manipulado pelo leitor, foram caracterizadas por conteúdos e formas distintas das formas mais exteriores, acessadas de modo facilitado.

A primeira edição do Ovo de Colombo é composta por quatro partes textuais, propriamente ditas. Há um corte, três dobras principais, sendo cada face utilizada para abrigar as diferentes seções, propriamente ditas. Mesmo levando-se em consideração as possibilidades de abertura do fanzine, o leitor seria levado a iniciar sua apreensão pelo texto que trata da publicação de maneira mais objetiva, assim como o breve texto que apresenta a proposta do objeto, definida como "design postal" (Figura 1). As áreas têm títulos contrastantes e uma massa de texto considerável. Os tipos foram datilografados, configurando maior similitude com publicações oficiais como jornais e revistas.

Contudo, acima do texto da "Proposta Design Postal", há uma dobradura triangular, remetendo a aba superior de um envelope. Na ponta dessa estrutura há um pequeno adesivo amarelo, que deveria ser rompido pelo leitor. O rompimento favoreceria a visualização da palavra "Oba!" em escrita cursiva, assim como a descoberta das demais áreas definidas por uma série de vincos e dobras. Nas áreas inicialmente obliteradas, encontram-se frases curtas, interferências gestuais e o pequeno retângulo com o desenho do ovo, mencionado anteriormente. 

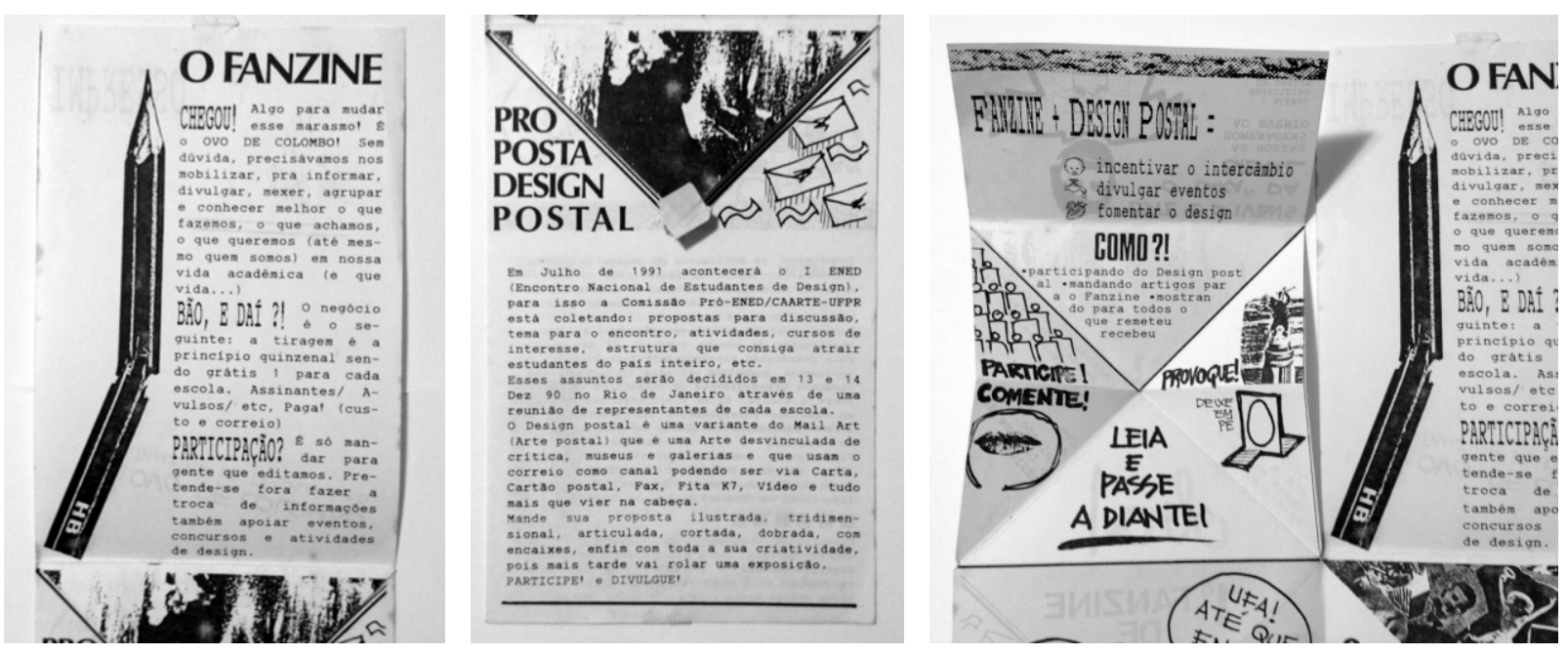

Figura 1 - Ovo de Colombo número 0.

Fonte: A autora.

$\mathrm{Na}$ segunda edição do fanzine, o formato mais vertical do objeto fechado leva naturalmente a parte mais "formal": ao editorial, créditos e texto convocatório em tom repreensivo. Já se o leitor abrisse a publicação no sentido oposto da leitura convencional, ou seja, da direita para a esquerda, teria acesso a uma série de "filipetas" com ilustrações diversas e textos curtos, convocações mais diretas e bemhumoradas, em tipografia gestual e ilustrada: "fanzine, encare essa", "Design Postal?! É só começar...Sele e remeta!", "Participe do ENED! Leia o fanzine”, " Faça design postal! Agite o seu C. A." (OVO DE COLOMBO, 1990, n. ${ }^{\circ}$ )

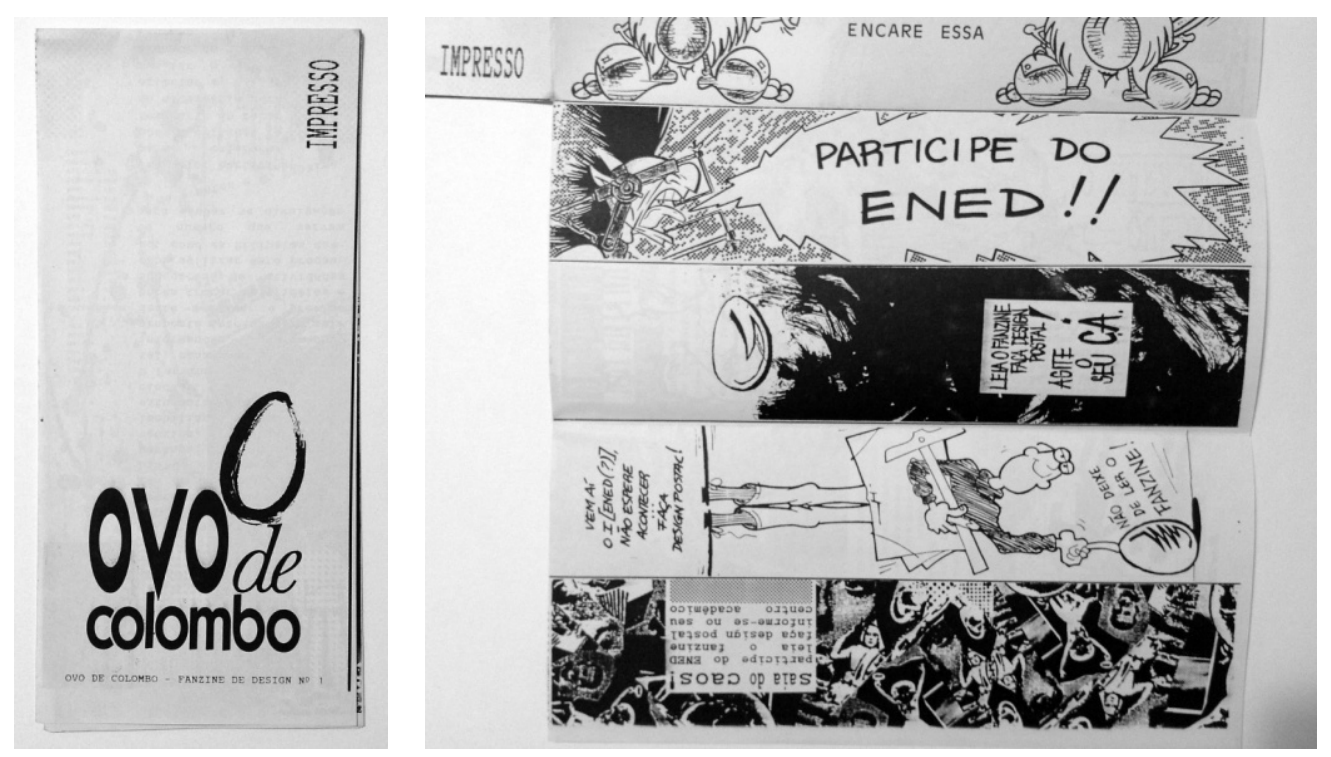

Figura 2 - Ovo de Colombo, Fanzine de Design $\mathrm{n}^{\circ} 1$.

Fonte: A autora. 

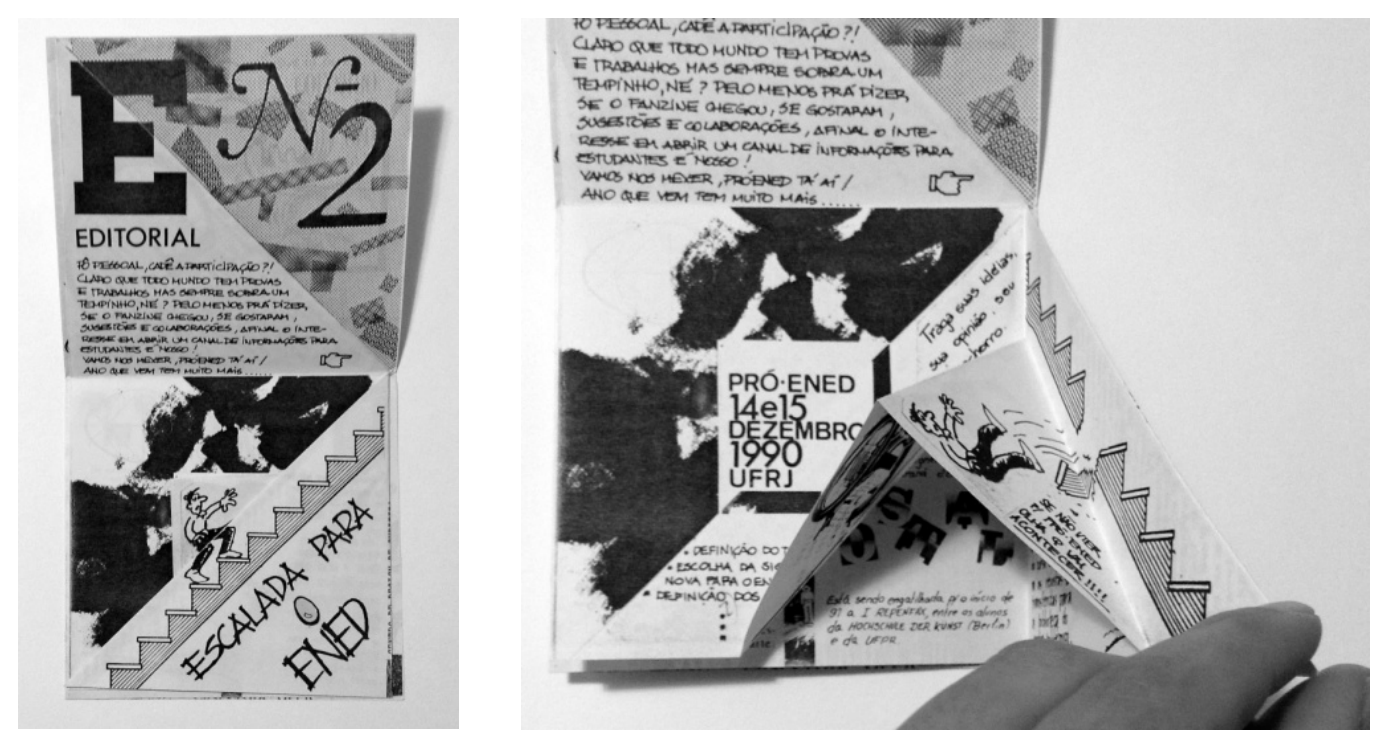

Figura 3 - Ovo de Colombo, Fanzine de Design n. ${ }^{\circ} 2$.

Fonte: A autora.

Em contrapartida, na terceira edição do fanzine Ovo de Colombo, os recursos gráficos mais informais, relacionados ao caráter lúdico que a publicação vinha ostentando, não estão mais escondidos. Logo que o fanzine é aberto, considerando-se a opção mais óbvia, revela-se o editorial com tipografia cursiva, assim como ilustrações e dobraduras que conferem, por meio de certa tridimensionalidade, a constituição de uma pequena narrativa sobre a "escalada para o ENED" (sigla que nomeava inicialmente o evento). (fig. 3)

A princípio, portanto, pode-se ressaltar que a cada edição os autores conquistaram maior propriedade na exploração das possibilidades da linguagem do fanzine, submetendo a importância institucional de um encontro oficial a uma codificação mais isenta e alternativa. Contudo, a cada edição aumenta a transposição de assuntos publicados na coluna de Ivens Fontoura.

Na primeira edição há somente menção a I Bienal Brasileira de Design, assunto constante nas matérias da coluna Designdesigner, enquanto referências quanto a origem da proposta "Design Postal" não é indicada. Na segunda edição do fanzine já há menção ao fato de Ivens Fontoura ter produzido matéria sobre o "Design Postal" e sobre o fanzine Ovo de Colombo, indicando a importância da legitimação da publicação por órgão oficial, promulgador do design em Curitiba. Além disso, nessa mesma edição do fanzine, transpõe-se imagem e parte do texto 
de matéria publicada em 21 de outubro de 1990, "O Design e o lixo que não é lixo", dedicada à ação, denominada como "repentina" (ou melhor, "a primeira repentina de design no país") realizada por alunos durante a I Bienal.

Já no fanzine Ovo de Colombo n. ${ }^{\circ}$ 2, a apresentação mais informal, baseada em ilustração e recursos interativos traz em suas faces "internas" uma espécie de resumo das matérias publicadas na Designdesigner. Há transcrição de parte da publicação sobre o "Centro de Design de Curitiba" (24 de junho de 1990) e adaptação de parte da matéria "Design postal com selo de qualidade" (28 de outubro de 1990). Os demais assuntos restringem-se a divulgação Design dos Novos (11 de novembro de 1990), e do prêmio Bom Desenho (referenciado pelo colunista no dia 25 de novembro do mesmo ano).

\section{CONSIDERAÇÕES FINAIS}

O discurso identitário empreendido pelo fanzine Ovo de Colombo, portanto, posicionava seus seguidores de maneira a assumir como necessária a importância do reconhecimento social no exercício do design. O modo como os fanzines foram estruturados materialmente constituíram pontos de identificação temporários relacionados à sedimentação da responsabilidade na continuidade de um projeto geral de identificação cultural. O espaço, pretensamente alternativo, foi sendo ocupado por informações oficiais da construção do campo do design.

Observa-se que estudantes responsáveis pela publicação do fanzine e pela realização do primeiro N Design na década de 1990, estão intimamente ligados ao fomento do design no Paraná atualmente, como professores ou também como membros ativos da PróDesign/PR e Centro Brasil Design. Contudo, como base na abordagem de Stuart Hall, as posições de identidade são definidas historicamente, e uma interpretação dessa relação, apesar de apresentar-se bastante tentadora, deveria levar em consideração especificidades que extrapolam e muito as pretensões deste trabalho. 


\section{REFERÊNCIAS}

BRAGA, Marcos da Costa. ABDI e APDINS-RJ: História das associações pioneiras do design no Brasil. São Paulo: Blucher Acadêmico, 2011.

BOURDIEU, Pierre. O poder simbólico. Rio de Janeiro: Bertrand Brasil, 2012.

BURKE, Peter. O que é história cultural. Rio de Janeiro: Zahar, 2008.

FONTOURA, Ivens. Além do sonho dos indivíduos, O Estado do Paraná, Curitiba, 30 set., 1990, Coluna Designdesigner, Almanaque, p. 8.

FONTOURA, Ivens. Curitiba também quer ver..., O Estado do Paraná, Curitiba, 9 set,. 1990, Coluna Designdesigner, Almanaque, p. 8.

FONTOURA, Ivens. Design postal com selo da qualidade, O Estado do Paraná. Curitiba, 28 out., 1990, Almanaque, p. 2.

FONTOURA, Ivens. Design dos Novos: UFPR-PUC/PR, O Estado do Paraná, Curitiba, 11 nov., 1990, Coluna Designdesigner, Almanaque, p. 7.

FONTOURA, Ivens. O design e o lixo que não é lixo. O Estado do Paraná. Curitiba, 21 out., 1990, Coluna Designdesigner, Almanaque, p. 5.

FONTOURA, Ivens. Por que Curitiba? O Estado do Paraná. Curitiba: 2 set., 1990.

FONTOURA, Ivens. Bom design da UFPR-I. O Estado do Paraná. Curitiba, 25 nov., 1990.

GALVÃO, Demetrios Gomes. Ressonâncias no meio do caminho e/ou no caminho do meio: a poética infame dos fanzines. In: Fanzines: autoria, subjetividade e invenção de si. Fortaleza: Edições UFC, 2010. p. 81-97.

HALL, Stuart; SILVA, Tomaz Tadeu; WOODWRAD; Kathryn. Identidade e diferença: a perspectiva dos Estudos Culturais. 11 ed. Petropolis: Vozes, 2012.

JULIER, Guy. La cultura del diseño. Barcelona: Editorial Gustavo Gili, 2010.

MUNIZ, Cellina Rodrigues. Na desordem da palavra: fanzines e a escrita de si. In: Fanzines: autoria, subjetividade e invenção de si. Fortaleza: Edições UFC, 2010. p. 15-27.

OVO DE COLOMBO. Fanzine de design número 0, Curitiba: 1990.

OVO DE COLOMBO. Fanzine de design número 1, Curitiba: 1990.

OVO DE COLOMBO. Fanzine de design número 2, Curitiba: 1990.

VASARI, Giorgio. Filippo Bruneleschi, escultor e arquiteto. In: Vida dos artistas. São Paulo: Editora WMF Martins Fontes, 2011. p. 225-251. 